\title{
Characterization of Binding of Human Fibrinogen to the Surface of Germ-tubes and Mycelium of Candida albicans
}

\author{
By ABDELHAMID BOUALI, RAYMOND ROBERT, * GUY TRONCHIN \\ AND JEAN-MARCEL SENET \\ Laboratoire d'Immunologie-Parasitologie-Mycologie, UFR des Sciences Médicales et \\ Pharmaceutiques, Section Pharmacie, 16 Bd Daviers, 49100 Angers, France
}

(Received 27 May 1986; revised 12 November 1986)

The binding of human fibrinogen to germ-tubes and mycelium of Candida albicans, forms usually found in infected tissues, was studied in vitro by an immunofluorescence assay. Binding was quantified by using ${ }^{125}$ I-labelled fibrinogen. The degree of binding differed according to the morphological form of the fungus. Binding relative to that of the yeast form was greater for mycelium (12-fold) than for germ-tube ( $7 \cdot 7$-fold). Pretreatment of yeasts with fragments $D$ and E (terminal degradation products of fibrinogen) before fibrinogen binding showed that fragment D possessed a higher affinity for $C$. albicans than fragment E. Binding of fibrinogen was diminished when $C$. albicans was pretreated with 2-mercaptoethanol alone or in combination with pronase, or pretreated with $\alpha$-mannosidase or trypsin. Binding was not decreased by pretreatment with pronase alone or chitinase. Inhibition experiments using $C$. albicans dialysed culture filtrate, $C$. albicans mannan, chitin, sugars or amino sugars were done by preabsorbing the fibrinogen with each of the above mentioned compounds. $C$. albicans dialysed culture filtrate inhibited the binding more strongly than $C$. albicans mannan. However, fibrinogen binding to $C$. albicans was not significantly reduced by mannose, several other sugars or chitin. These studies demonstrate the existence of a fibrinogen-binding factor (FBF) strongly associated with the surface of germ-tube and filamentous forms of $C$. albicans, and indicate a possible role for FBF in the pathogenicity of $C$. albicans.

\section{INTRODUCTION}

Candida albicans is a dimorphic pathogen. As a commensal, it grows primarily as a yeast (blastospores), but in infected tissues, blastospores and filamentous forms are simultaneously found (Odds, 1979). The mycelium, initiated by germ-tubes, plays a role in the pathogenicity of C. albicans, particularly in colonization of the host. Kimura \& Pearsall (1980) have shown that the degree of fungal adherence to host epithelial cells is correlated with the formation of germtubes.

The interactions of $C$. albicans with serum proteins are of considerable interest, since exposure of $C$. albicans to mammalian serum results in a variety of morphological effects, such as germtube induction (Taschdjian et al., 1960; Hasenclever, 1978). Ray \& Wuepper (1976) have demonstrated that $C$. albicans activates the alternative complement pathway, resulting in the formation of chemotactic factors, and Kozutsumi et al. (1980) isolated a protein from rabbit serum which binds to yeast mannan (MBP). MBP has the properties of a lectin and may have a role in defence against pathogenic yeasts (Bull \& Turner, 1984). An analogous binding protein was isolated from human and bovine sera (Kawasaki et al., 1985). A role for coagulation proteins in the pathogenicity of $C$. albicans has been little documented, although envisaged by Maisch \& Calderone (1981), who examined adherence of C. albicans to a fibrin-platelet matrix formed in 
vitro, and by Philippidis et al. (1971) and Kambayashi et al. (1983), who reported that severe $C$. albicans septicaemia can induce a disseminated intravascular coagulation.

For other micro-organisms, the role of coagulation factors and especially of fibrinogen has been studied. Espersen et al. (1984) demonstrated the enhancing effect of human fibrinogen on the virulence of Staphylococcus aureus in mice. More recently, Chhatwal et al. (1985) reported binding of human fibrinogen to groups A, B, C and G streptococci, and demonstrated that fibrinogen binding inhibited fixation of the third component of human complement on the bacterial surface.

In the present study, binding of human fibrinogen to the surface of germ-tubes and mycelium of $C$. albicans was investigated by immunofluorescence and quantified by using ${ }^{125}$ I-labelled fibrinogen. The effect of various inhibitors and enzymes pretreatment on binding was also studied.

\section{METHODS}

Organisms and culture conditions. Candida albicans 1066 (serotype A) originally isolated from a case of candida septicaemia was used throughout. Blastospores were grown at $37^{\circ} \mathrm{C}$ on Sabouraud glucose agar (Merck) for $24 \mathrm{~h}$. Germ-tubes amd mycelium were obtained by incubation of 24-h-old blastospores for various times $(1,2,4,8$ and $24 \mathrm{~h}$ ) at $37^{\circ} \mathrm{C}$ in Medium 199 (Flow Laboratories).

Immunofluorescence assay. Two sources of fibrinogen were used: (i) purified human fibrinogen, free of factor XIII (Diagnostica stago) and (ii) whole fresh human plasma.

Fungal elements were washed twice in $0.15 \mathrm{M}$-phosphate-buffered saline (PBS), $\mathrm{pH} 7 \cdot 2$, containing $5 \%(\mathrm{w} / \mathrm{v})$ sodium citrate (PBSC) and adjusted to $5 \times 10^{6}$ cells ml-1. Portions $(0.1 \mathrm{ml})$ of suspension were centrifuged at $500 \mathrm{~g}$ for $15 \mathrm{~min}$ and the pellets were resuspended in $0.2 \mathrm{ml}$ purified fibrinogen solution $\left(0.25 \mathrm{mg} \mathrm{ml}^{-1}\right.$ in PBSC) or in $0.2 \mathrm{ml}$ whole fresh plasma. After $30 \mathrm{~min}$ incubation at $37^{\circ} \mathrm{C}$, the fungi were washed twice in PBS and resuspended in $50 \mu \mathrm{l} \mathrm{PBSC}$. One drop $(20 \mu \mathrm{l})$ was placed on a microscope slide and allowed to dry. Then $20 \mu \mathrm{l}$ rabbit anti-human fibrinogen serum (Diagnostica stago) at $1 / 100$ dilution in PBSC was added. Slides were placed in a moist chamber; incubated for $30 \mathrm{~min}$ at $37^{\circ} \mathrm{C}$ and washed three times in PBSC. Fluorescein-isothiocyanate-conjugated goat antirabbit IgG ( $20 \mu \mathrm{l} 1 / 100$ dilution; Biosis) was added. Slides were incubated for $30 \mathrm{~min}$ at $37^{\circ} \mathrm{C}$, washed three times in PBSC and mounted in PBS containing $90 \%(\mathrm{v} / \mathrm{v})$ glycerol. They were observed under a Nikon microscope equipped for epifluorescence.

${ }_{125}$ I-Labelled fibrinogen binding assay. Human fibrinogen radiolabelled with ${ }^{125} \mathrm{I}$ (specific activity, $137.5 \mu \mathrm{Ci} \mathrm{mg}^{-1}, 5.09 \mathrm{MBq} \mathrm{mg}^{-1}$ ) was from Amersham. Fungal cells $(24 \mathrm{~h}$ blastospores, $2 \mathrm{~h}$ germ-tubes and $24 \mathrm{~h}$ mycelium were washed twice in PBSC. The reaction mixture consisted of $0.1 \mathrm{ml} 8 \%(\mathrm{v} / \mathrm{v})$ fungal suspension and $0.1 \mathrm{ml}^{125} \mathrm{I}$-labelled fibrinogen $\left(500 \mathrm{\mu g} \mathrm{ml}^{-1}\right)$. After incubation for $30 \mathrm{~min}$ at room temperature the fungi were sedimented by centrifugation ( $15 \mathrm{~min}$ at $2000 \mathrm{~g}$ ) and were washed six times in PBSC. Radioactivity in the sediment was measured in a $\gamma$-spectrometer (Kontron MDA 312). For determination of surface areas, a blastospore was considered as a microsphere ( $5 \mu \mathrm{m}$ diameter), while a germ-tube was considered as a cylinder ( $3 \mu \mathrm{m}$ diameter and $15 \mu \mathrm{m}$ length) plus a microsphere of $5 \mu \mathrm{m}$ diameter. Mycelium was considered as a cylinder of $5 \mu \mathrm{m}$ diameter and $250 \mu \mathrm{m}$ length. For germ-tubes, the surface area used for determinations was the tube surface only. Data presented are mean values from triplicate experiments.

Competitive binding by fibrinogen fragments $D$ and $E$. Competitive binding to the surface of 24-h-old mycelium was investigated between non-radiolabelled fibrinogen fragments $D$ or $E$ (Diagnostica stago) and ${ }^{125}$ I-labelled fibrinogen. In the first phase of the assay, mycelial cells $(0.1 \mathrm{ml})$ were incubated with $50 \mu \mathrm{l}$ fragment $\mathrm{D}$ or fragment $\mathrm{E}\left(3-50 \mu \mathrm{g} \mathrm{ml}^{-1}\right)$ for $30 \mathrm{~min}$ at room temperature. In the second stage, $50 \mu \mathrm{l}^{125}$ I-labelled fibrinogen $\left(100 \mu \mathrm{g} \mathrm{ml}^{-1}\right)$ was added. After incubation for $30 \mathrm{~min}$ at room temperature, the mycelium was washed six times in PBSC by centrifugation ( $15 \mathrm{~min}$ at $2000 \mathrm{~g}$ ), and the radioactivity in the sediment was measured.

Binding inhibition assays. Reaction mixtures consisted of $50 \mu \mathrm{l}$ iodinated $\left({ }^{125} \mathrm{I}\right)$ fibrinogen $\left(100 \mu \mathrm{g} \mathrm{ml}^{-1}\right)$ and $50 \mu \mathrm{l}$ inhibitor at different concentrations. After $30 \mathrm{~min}$ at room temperature, $0 \cdot 1 \mathrm{ml} 24$-h-old mycelial suspension $(8 \%$, $\mathrm{v} / \mathrm{v}$ ) was added and the radioactivity in the sediment was measured after $30 \mathrm{~min}$ of contact at room temperature and several washings. The following substances were tested for their possible inhibitory effect. (i) Culture filtrate from C. albicans 1066, grown for $48 \mathrm{~h}$ in Medium 199, extensively dialysed against distilled water and lyophilized. The dialysed culture filtrate consisted of $30 \%$ protein. Protein was measured by the Lowry method using BSA as a standard. (ii) Mannan, prepared from blastospores of $C$. albicans 1066 by the method of Peat et al. (1961). (iii) Chitin (from crab shells; Sigma). (iv) Sugars and amino sugars $[\mathrm{D}(+)$-glucose, $\mathrm{D}(+)$-galactose, $\mathrm{D}(+)$-mannose, $N$ acetyl-D-glucosamine and $N$-acetyl-D-galactosamine; all from Sigma].

Exposure of mycelial surface to 2-mercaptoethanol and enzymes. SH-Reducing treatment. Washed mycelium $(1 \mathrm{mg})$

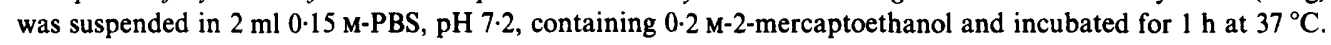
Pronase E treatment. The mycelium $\left(1 \mathrm{mg}\right.$ ) was treated for $1 \mathrm{~h}$ at $37^{\circ} \mathrm{C}$ with $250 \mu \mathrm{g}$ pronase $\mathrm{E}$ (Merck) and $0.2 \mathrm{M}-2-$ mercaptoethanol in 0.15 M-PBS, pH 7.6, (2 ml). Some mycelium was treated with pronase $E$ without the reducing 
agent. Trypsin treatment. The mycelial suspension ( $1 \mathrm{mg}$ in $2 \mathrm{ml} 0 \cdot 15 \mathrm{M}$-sodium phosphate buffer, $\mathrm{pH} 7 \cdot 6)$ was incubated for $1 \mathrm{~h}$ at $37^{\circ} \mathrm{C}$ with $250 \mu \mathrm{g}$ trypsin (Merck). $\alpha$-Mannosidase treatment. The mycelium ( $\left.1 \mathrm{mg}\right)$ was treated

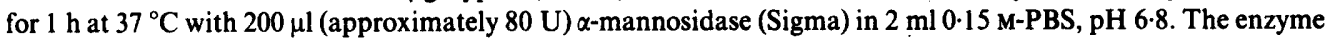
was dialysed against distilled water before use. The preparation of enzyme contained less than $0.05 \%$ proteases, $\beta$ galactosidase, $\alpha$-galactosidase and $\beta$ - $N$-acetylglucosaminidase. Chitinase treatment. The mycelium ( $1 \mathrm{mg}) \mathrm{was}$ treated for $1 \mathrm{~h}$ at $37^{\circ} \mathrm{C}$ with $250 \mu \mathrm{g}$-chitinase (Calbiochem) in $2 \mathrm{ml} 0 \cdot 15 \mathrm{M}$-sodium phosphate buffer, pH 5.5.

For each treatment, control samples using buffer without enzymes were incubated for $1 \mathrm{~h}$ at $37^{\circ} \mathrm{C}$. After different treatments, mycelium was carefully washed in $0.15 \mathrm{M}$-PBS containing $0.6 \mathrm{M}-\mathrm{KCl}$ as osmotic stabilizer, and was used in immunofluorescence and in ${ }^{125} \mathrm{I}$-labelled fibrinogen binding assays.

\section{RESULTS}

Binding of fibrinogen to C. albicans

A study of the binding of fibrinogen to $C$. albicans by immunofluorescence indicated that no non-budding blastospores showed binding. Of the budding blastospores, produced under budding conditions or under hyphae-inducing conditions, only a few exhibited a strong fluorescence of their emerging bud. Fig. $1(e)$ shows a fluorescent bud and a fluorescent hypha emerging from a parent yeast under hyphae-inducing conditions. After $1 \mathrm{~h}$ (Fig. $1 a$ ) or $2 \mathrm{~h}$ (Fig. $1 b)$ germ-tubes showed very strong binding on all the surface of the emerging element. The fluorescence exhibited was mostly homogeneous (Fig. 1 $d$ ) and 8-h-old mycelium (Figs $1 e$ and $f$ ) was also very strongly fluorescent. In 3-d-old mycelium (Fig. 1c) cell-wall fluorescence was heterogeneous and diminished compared with newly-formed germ-tubes (Figs $1 a$ and $b$ ). A study by immunofluorescence assay of fibrinogen binding with whole fresh plasma gave binding patterns identical to those obtained with pure fibrinogen.

Binding of ${ }^{125} \mathrm{I}$-labelled fibrinogen confirmed the observations from immunofluorescence microscopy. When the surface area of fungus exposed to fibrinogen was used as the denominator for measurement of binding, the mean value for the number of bound fibrinogen molecules per $\mathrm{mm}^{2}$ was $34 \times 10^{7} \pm 2 \times 10^{7}(\mathrm{SD})$ for blastospores, $265 \times 10^{7} \pm 6 \times 10^{7}(\mathrm{SD})$ for germ-tubes and $408 \times 10^{7} \pm 9 \times 10^{7}$ (SD) for mycelium. Thus, fibrinogen binding relative to that of blastospores was 12 times greater for mycelium and $7 \cdot 7$ times greater for germ-tubes.

A study of the capacity of mycelium to bind fibrinogen (Fig. 2) showed that, for $8 \mu$ l fungal material, $100 \%$ binding was obtained from $250 \mu \mathrm{g}$ radiolabelled fibrinogen $\mathrm{ml}^{-1}$ (final concentration). In the following inhibition experiments, the [ $\left.{ }^{125} \mathrm{I}\right]$ fibrinogen concentration used was $25 \mu \mathrm{g} \mathrm{ml}^{-1}$, corresponding to $33 \%$ binding.

\section{Fibrinogen binding after binding of fibrinogen fragments $D$ and $E$}

The binding of fibrinogen fragments on the mycelial surface of $C$. albicans depended on the concentrations used (Fig. 3). The binding of fragments D or E is expressed as the percentage inhibition of radiolabelled fibrinogen binding. For $50 \mu \mathrm{g} \mathrm{ml}^{-1}$ of these fragments, inhibition of binding was easily obtained with fragment D ( $52 \%$ inhibition), but only moderately with fragment $\mathrm{E}(11 \%$ inhibition).

\section{Inhibition of fibrinogen binding by yeast extracts and other substances}

Only dialysed culture filtrate strongly inhibited the fibrinogen binding. Thus $75 \%$ inhibition was observed with $250 \mu \mathrm{g}$ filtrate (Fig. 4). At the same concentration, the observed inhibition with mannan extracted from C. albicans (Fig. 4) was less strong (38\%). Slight inhibition was observed with chitin ( $\leqslant 7 \%$ inhibition with $250 \mu \mathrm{g}$ ) (Fig. 4). The specificity of the inhibition was tested by examining the effect of other constituents on binding. Mannose, a constituent of mannan, was not inhibitory. All other sugars $[D(+)$-glucose and $D(+)$-galactose] and amino sugars [ $N$-acetyl-D-glucosamine and $N$-acetyl-D-galactosamine] tested did not inhibit fibrinogen binding. 

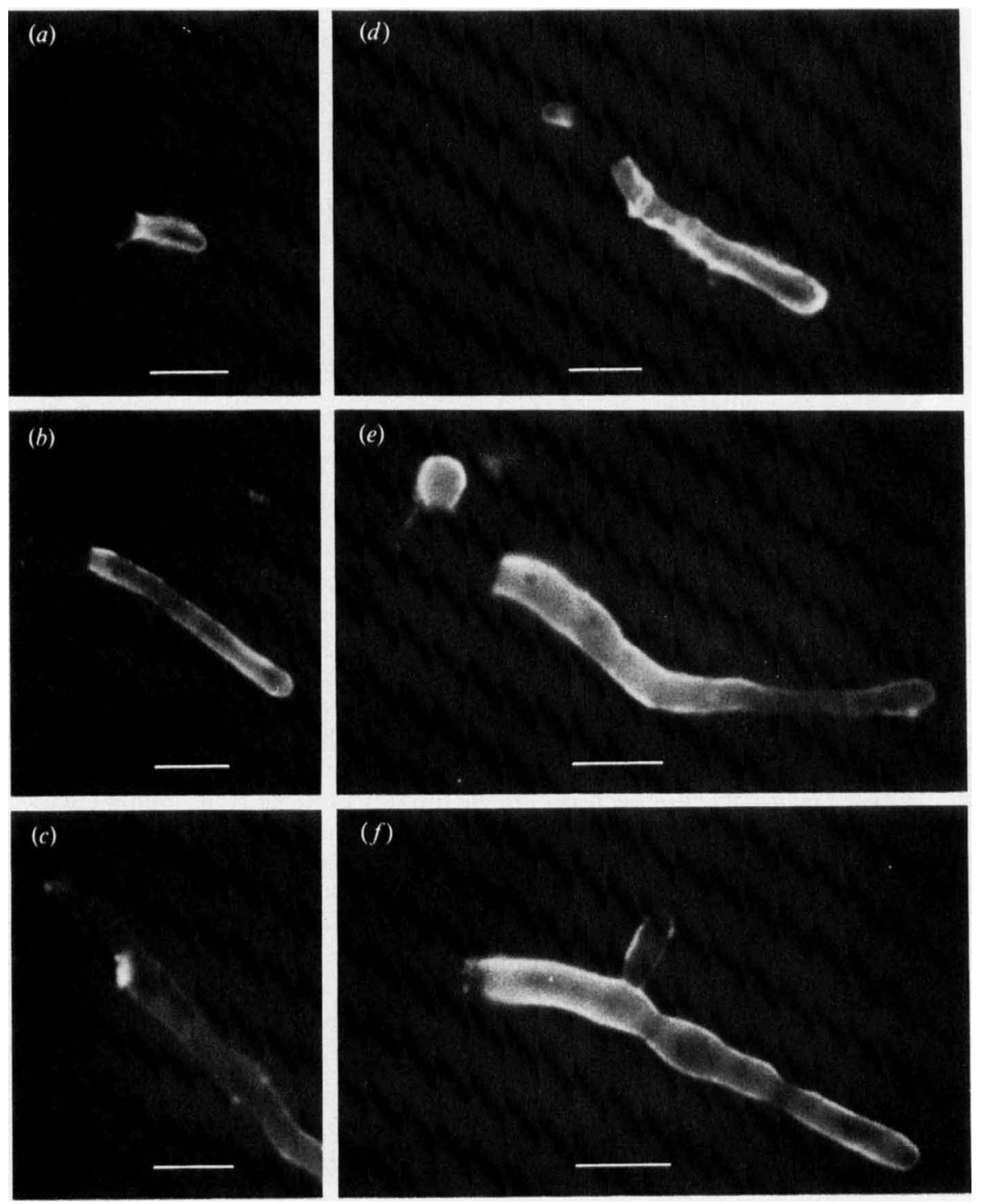

Fig. 1. Stages in the development of germ-tubes and mycelium from blastospores of $C$. albicans, as seen by immunofluorescence microscopy of fibrinogen-treated organisms. For explanation, see text. Bars, $10 \mu \mathrm{m}$.

\section{Effects of 2-mercaptoethanol and pretreatment with enzymes}

The binding of fibrinogen to $C$. albicans was quantified after treatment of 24 -h-old mycelium with pronase $\mathrm{E}$ alone, pronase $\mathrm{E}$ and $0.2 \mathrm{M}$-2-mercaptoethanol, $0.2 \mathrm{M}$-2-mercaptoethanol alone, trypsin, $\alpha$-mannosidase or chitinase (Table 1). Pronase E enhanced fibrinogen binding, and chitinase did not reduce binding significantly, but $\alpha$-mannosidase, trypsin, 2-mercaptoethanol and 2-mercaptoethanol + pronase resulted in a significant loss of fibrinogen-binding activity.

\section{DISCUSSION}

The binding of host proteins, particularly of human fibronectin (Skerl et al., 1984), to blastospores of $C$. albicans is considered to play a role in adherence of $C$. albicans to mammalian cells. With human fibrinogen, the present study demonstrated that binding can be obtained with 


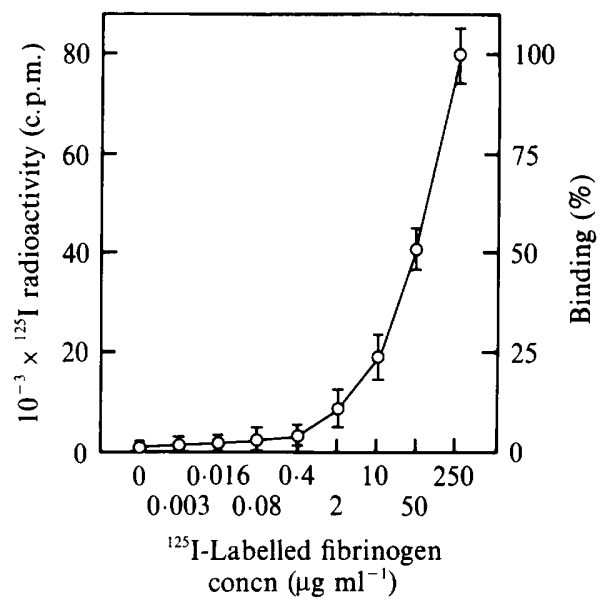

Fig. 2. Measurement of [ $\left.{ }^{125} I\right]$ fibrinogen binding to mycelium of $C$. albicans. Each point represents a mean of duplicates for one [ $\left.{ }^{125} \mathrm{I}\right]$ fibrinogen concentration. Vertical bars represent SD. For conditions of incubation see Methods.

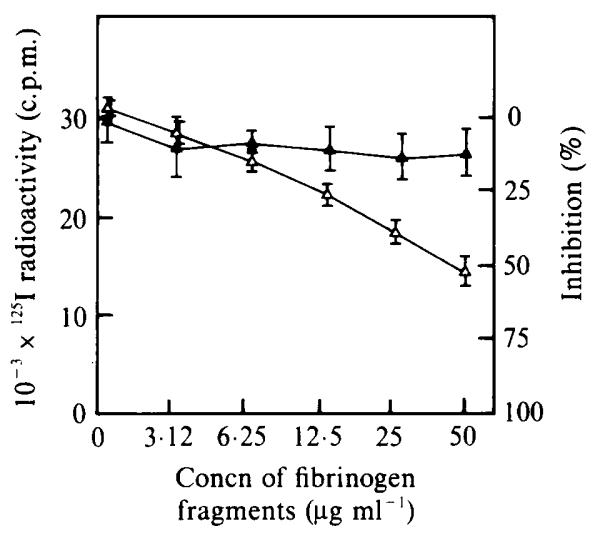

Fig. 3

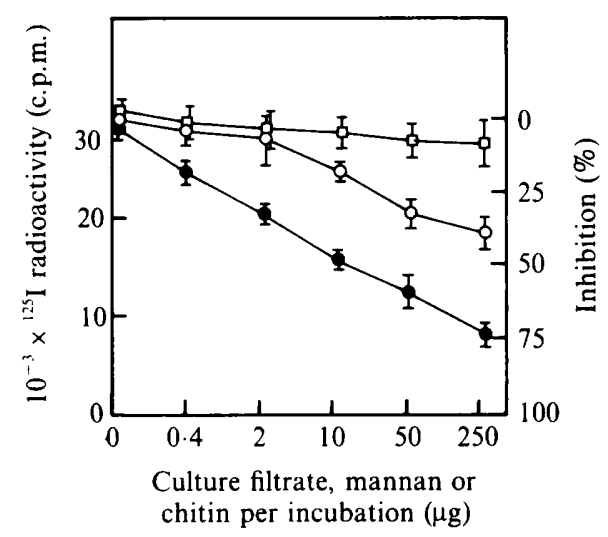

Fig. 4

Fig. 3. Inhibition of fibrinogen binding to C. albicans by preincubation of the mycelium with fragment $\mathrm{E}(\Delta)$ or fragment $\mathrm{D}(\triangle)$ of human fibrinogen. Each point represents a mean of triplicate experiments. Vertical bars represent SD. For conditions of incubation see Methods.

Fig. 4. Inhibition of fibrinogen binding to mycelium of $C$. albicans by preabsorbing the fibrinogen with C. albicans culture filtrate $(\bigcirc)$, mannan $(O)$ and chitin $(\square)$. Each point represents a mean of triplicate experiments. Vertical bars represent SD. For conditions of preabsorbing see Methods.

filamentous forms (germ-tubes and mycelium). However, we could observe with only a few budding cells the binding of fibrinogen at their buds; no binding was observed with mother cells. The fibrinogen-binding factor $(\mathrm{FBF})$ appeared early during germ-tube formation; it was detected within $30 \mathrm{~min}$ and disappeared as the mycelium aged. These observations were probably associated with the ultrastructural changes in the cell wall during germ-tube formation from blastospores of C. albicans (Cassone et al., 1973). The binding of fibrinogen to the filamentous forms, usually found in infected tissues (Odds, 1979) and implicated in adherence processes (Kimura \& Pearsall, 1980), may suggest a role for FBF in the pathogenicity of $C$. albicans. The FBF could account for adherence of $C$. albicans to the fibrin-platelet matrix formed in vitro, as demonstrated by Maisch \& Calderone $(1980,1981)$. In addition, this binding was not inhibited by plasma components. The binding site of fibrinogen is probably located on fragment $D$ 
Table 1. Effect of treatment with 2-mercaptoethanol and enzymes on fibrinogen binding to $C$. albicans mycelial surface

\begin{tabular}{lcc}
\multicolumn{1}{c}{ Pretreatment } & $\begin{array}{c}\text { Percentage of } \\
\text { [125I]fibrinogen } \\
\text { binding } \pm \text { SD } \dagger\end{array}$ & $\begin{array}{c}\text { Relative } \\
\text { binding } \ddagger\end{array}$ \\
PBSC & $44 \pm 5$ & $1 \cdot 0$ \\
Pronase E & $56 \pm 7$ & 1.3 \\
2-Mercaptoethanol & $13 \pm 2$ & 0.3 \\
Pronase E and & $16 \pm 2$ & 0.4 \\
2-mercaptoethanol & $24 \pm 3$ & 0.5 \\
Trypsin & $18 \pm 2$ & 0.4 \\
$\alpha$-Mannosidase & $38 \pm 4$ & 0.9 \\
Chitinase & &
\end{tabular}

* For conditions of treatment with hydrolytic enzymes see Methods.

$\dagger$ Data presented are mean values from triplicate experiments \pm SD. C. albicans treated with buffer without enzymes or SH-reducing agent served as the control.

$\ddagger$ Binding relative to that of mycelium treated with PBSC.

because this has a higher affinity for $C$. albicans than fragment E. Pretreatment of germ-tubes with 2-mercaptoethanol alone or in combination with pronase decreased fibrinogen binding, but the difference between the two pretreatments was not significant (Table 1). It seems possible that 2-mercaptoethanol releases the FBF. These results are comparable with the observations of Davies \& Wayman (1975) and Chattaway et al. (1976) in which 2-mercaptoethanol was found to release a large amount of cell wall material from $C$. albicans blastospores. These released components may be implicated in concanavalin A agglutination (Cassone et al., 1978; Tronchin et al.; 1981). Pretreatment with trypsin also decreased fibrinogen binding. The role of other cell wall components was studied. Preatreatment with chitinase gave no significant decrease in fibrinogen binding, but $\alpha$-mannosidase released mannose from the cell wall of $C$. albicans and decreased the binding.

Mannan and proteins may be components of FBF. However, purified mannan did not significantly inhibit the binding at low concentration and inhibition was obtained only at high concentration. With dialysed culture filtrate of $C$. albicans, on the other hand, a strong binding inhibition was obtained even at low concentration (Fig. 4). These results confirm that proteins and glycosidic components present on the mycelial surface are involved in fibrinogen binding.

The authors are grateful to Dr D. W. R. Mackenzie (PHLS Mycological Reference Laboratory, London) for reading the manuscript.

\section{REFERENCES}

Bull, F. G. \& TURner; N. R. (1984). A serum mannan-binding protein and candidiasis. Sabouraudia 22, 347-350.

Cassone, A., Simonetit, N. \& Strippoli, V. (1973). Ultrastructural changes in the wall during germ-tube formation from blastospores of Candida albicans. Journal of General Microbiology 77, 417-426.

Cassone, A., Mattia, E. \& Boldrini, L. (1978). Agglutination of blastospores of Candida albicans by concanavalin $\mathrm{A}$ and its relationship with the distribution of mannan polymers and the ultrastructure of the cell wall. Journal of General Microbiology 105, 263-273.

Chattaway, F. W., Shenolikar, S., O'Reilly, J. \& BARLOW, A. J. E. (1976). Changes in the cell surface of the dimorphic forms of Candida albicans by treatment with hydrolytic enzymes. Journal of General Microbiology 95, 335-347.
ChHatwal, G. S., Dutra, I. S. \& Blobel, H. (1985). Fibrinogen binding inhibits the fixation of the third component of human complement on surface of groups A, B, C, and G streptococci. Microbiology and Immunology 29, 973-980.

Davies, R. \& Wayman, F. J. (1975). The effect of thiols on Saccharomyces fragilis. Antonie van Leeuwenhoek 41, 33-58.

Espersen, F., Clemmensen, I., Frimodt-Moller, N. \& JENSEN, K. (1984). Effect of human IgG and fibrinogen on Staphylococcus aureus intraperitoneal infection in mice. Acta pathologica, microbiologica et immunologica scandinavica 92, 311-317.

HASENCLEVER, H. F. (1978). The in vitro interactions of Candida albicans with non specific serum proteins. Mycopathologia 65, 169-176.

Kambayashi, J., Kosaki, G. \& Shimada, Y. (1983). Disseminated intravascular coagulation associated 
with severe infection in surgical patients: a retrospective and prospective study. Bibliotheca haematologica 25, 49-58.

Kimura, L. H. \& Pearsall, N. N. (1980). Relationship between germination of Candida albicans and increased adherence to human buccal epithelial cells. Infection and Immunity 28, 464-468.

Kozutsumi, Y., Kawasaki, T. \& Yamashima, I. (1980). Isolation and characterization of a mannanbinding protein from rabbit serum. Biochemical and Biophysical Research Communications 95, 658-664.

KaWASAKI, N., KaWASAKI, T. \& Yamashina, I. (1985). Mannan-binding protein and conglutinin in bovine serum. Journal of Biochemistry 98, 1309-1320.

Maisch, P. A. \& Calderone, R. A. (1980). Adherence of Candida albicans to a fibrin-platelet matrix formed in vitro. Infection and Immunity 27, 650-656.

Maisch, P. A. \& Calderone, R. A. (1981). Role of surface mannan in the adherence of Candida albicans to fibrin-platelet clots formed in vitro. Infection and Immunity 32, 92-97.

ODDs, F. C. (1979). Candida and Candidosis. Baltimore: University Park Press.

Peat, S., Whelan, W. J. \& Edwards, T. E. (1961).
Polysaccharides of baker's yeast. IV. Mannan. Journal of the Chemical Society 1, 29-34.

Philippidis, P., Naiman, J. L., Sibinga, M. S. \& VALDESDAPNEA, M. A. (1971). Disseminated intravascular coagulation in Candida albicans septicemia. Journal of Pediatrics 78, 683-686.

RAY, T. L. \& WUEPPER, D. (1976). Activation of the alternative (properdin) pathway of complement by Candida albicans and related species. Journal of Investigative Dermatology 67, 700-703.

Skerl, K. G., Calderone, R. A., Segal, E., SreevalSAN, T. \& SCHELD, W. M. (1984). Iri vitro binding of Candida albicans yeast cells to human fibronectin. Canadian Journal of Microbiology 30, 221-227.

Taschdjian, C., Burchall, J. \& KozinN, P. (1960). Rapid identification of Candida albicans by filamentation on serum and serum substitutes. American Journal of Diseases of Children 99, 212.

Tronchin, G., Poulain, D., Herbaut, J. \& Biguet, J. (1981). Cytochemical and ultrastructural studies of Candida albicans. II. Evidence for a cell wall coat using concanavalin A. Journal of Ultrastructure Research 75, 50-59. 